\title{
MPPT Using P\&O and IC Based PI Controller for Solar PV System with Charge Controller
}

\author{
${ }^{* 1}$ B. Lakshmi, ${ }^{2}$ M.S.Sujatha, ${ }^{3}$ N.M.G.Kumar, ${ }^{4}$ N.Girish \\ ${ }^{1,2,3}$ Center for Energy, Department of Electrical and Electronics Engineering, Sree Vidyanikethan Engineering \\ College, Tirupati \\ ${ }^{4}$ Department of Electronics and Instrumentation Engineering, Sree Vidyanikethan Engineering College, Tirupati \\ Email:lakshmi3019@gmail.com,Sujatha.machineni@gmail.com,nmgkumar@gmail.com, \\ naminenigirish@gmail.com
}

Received: 06th December 2019, Accepted: 20th January 2020, Published: 30th April 2020

\begin{abstract}
The power output of the solar PV system depends mainly on the two variables such as temperature and irradiance. A technique for the effective use of solar PV is known as the MPPT. This technique extracts the highest available energy from the solar PV panel by enabling it to operate at the maximum effective output. This paper introduces 2 MPPT controllers that are standard Perturb \& Observe (P\&O) and Proportional Integral (PI). In specific, the performance of the controllers under two conditions is analyzed such as constant irradiation and different temperatures, constant temperature and different irradiations. The simulation work is carried out under MATLAB/SIMULINK, environment.
\end{abstract}

\section{Keywords}

PV System, Perturb \& Observe (P \& O), Proportional Integral (PI), Maximum Power Point Tracking (MPPT), DCDC Converters.

\section{Introduction}

Present days, growth of natural resources, in particular solar power has received a great deal of global attention owing to its sustainability, maintenance-free and noise-free features, etc. However, the operation of solar PV devices is extremely dependent on external variables, like solar irradiance and temperature, which have enormous consequences for the production of PV devices. Therefore, MPPT controllers are necessary to maintain effective operation of PV modules in the solar PV system [1]. From the literature it is observed that many techniques are available for MPP tracking.

Perturb \& Observe technique was more appropriate for other MPPT controllers because it is a standard method [2], it provides better efficiency under altering climate circumstances. The drawbacks of P\&O method are more oscillations and extended commutation time. The proposed Incremental Conductance based PI controller is used to solve the above problems. The suggested technique delivers the rapid response under climatic circumstances. The photovoltaic technique comprises of photovoltaic modules and DC-to-DC converters [3]. The PV system's V\&I output is given to the MPPT, which generates a duty cycle. Constant voltage and current techniques are used for charging the battery. This will enhance the life cycle of the battery and reduces the losses. The voltage and current of the buck converter are kept constant with the assistance of the PI controller.

\section{Solar PV System}

The photovoltaic system converts sunlight energy into electricity. Fig.1 shows the single diode of photo-voltaic module [4].

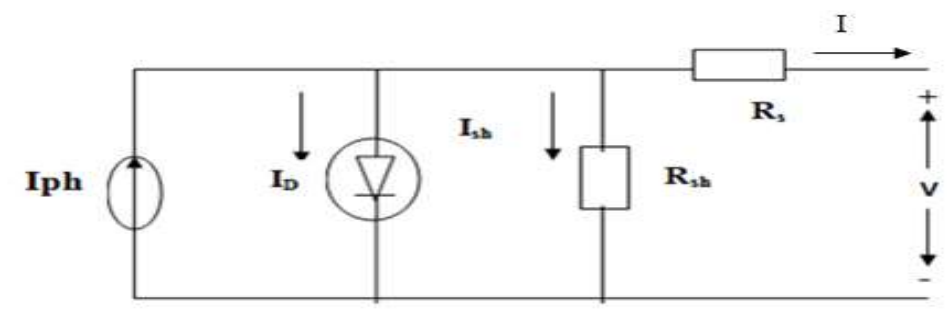

Fig 1: Solar PV Cell

The current (I) of the solar photovoltaic system is calculated on the basis of equation 1 .

$I=I_{p h}-I_{D}-I_{s h}$ 
Based on equation 2, the diode characteristic equation $\left(\mathrm{I}_{\mathrm{D}}\right)$ is calculated.

$$
I_{D}=I_{S}\left[\exp \left(\frac{q\left(V_{L}+I_{L} R_{S}\right)}{n K T}\right)-1\right]
$$

The leakage shunt current $\left(\mathrm{I}_{\text {sh }}\right)$ is calculated on the basis of equation 3 .

$$
I_{s h}=\frac{V_{L}+I_{L} R_{s}}{R_{s h}}
$$

Here, $R_{S}$ is the series resistance $\& R_{s h}$ is the shunt resistances; $\mathrm{I}_{\mathrm{D}}$ is the diode current; $V_{L}$ is the load voltage; $\mathrm{n}$ is ideality factor; $\mathrm{K}$ is the constant of Boltzmann, $\mathrm{q}$ is the electron charge and $\mathrm{T}$ is the temperature of the cell. Equation (4) will obtain from equations (2), (3) and (1).

$I=I_{p h}-I_{S}\left[\exp \left(\frac{q\left(V_{L}+I_{L} R_{S}\right)}{n K T}\right)-1\right]-\frac{V_{L}+I_{L} R_{S}}{R_{S h}}$

\section{P \& O Based MPPT}

The Perturb\& Observe MPPT technique is most commonly utilized in photovoltaic system applications, due to its easy execution and simplicity. It's an iterative approach for obtaining the MPP. It measures a photovoltaic module current and voltage, and then perturbs the working point of a solar module to determine the exchange of path. Flow diagram of $\mathrm{P} \& \mathrm{O}$ method is shown in Fig.2 [5].

Step1: Measure current and voltage values for solar PV system.

Step 2: Calculate power $\mathrm{P}(\mathrm{k})=\mathrm{V}(\mathrm{k})^{*} \mathrm{I}(\mathrm{k})$ and change of power $\Delta \mathrm{p}=\mathrm{p}(\mathrm{k})-\mathrm{p}(\mathrm{k}-1)$.

Step 3: Check for the condition $\Delta \mathrm{p}>0$.

Step 4: If $\Delta p>0$ the operating voltage rises,else the operating voltage will reduce.

The power value may reduce or increase, depending on the above circumstances and move nears the maximum power point. During voltage \& current fluctuations, the step size is kept higher by using P \& O method $[6,10]$.

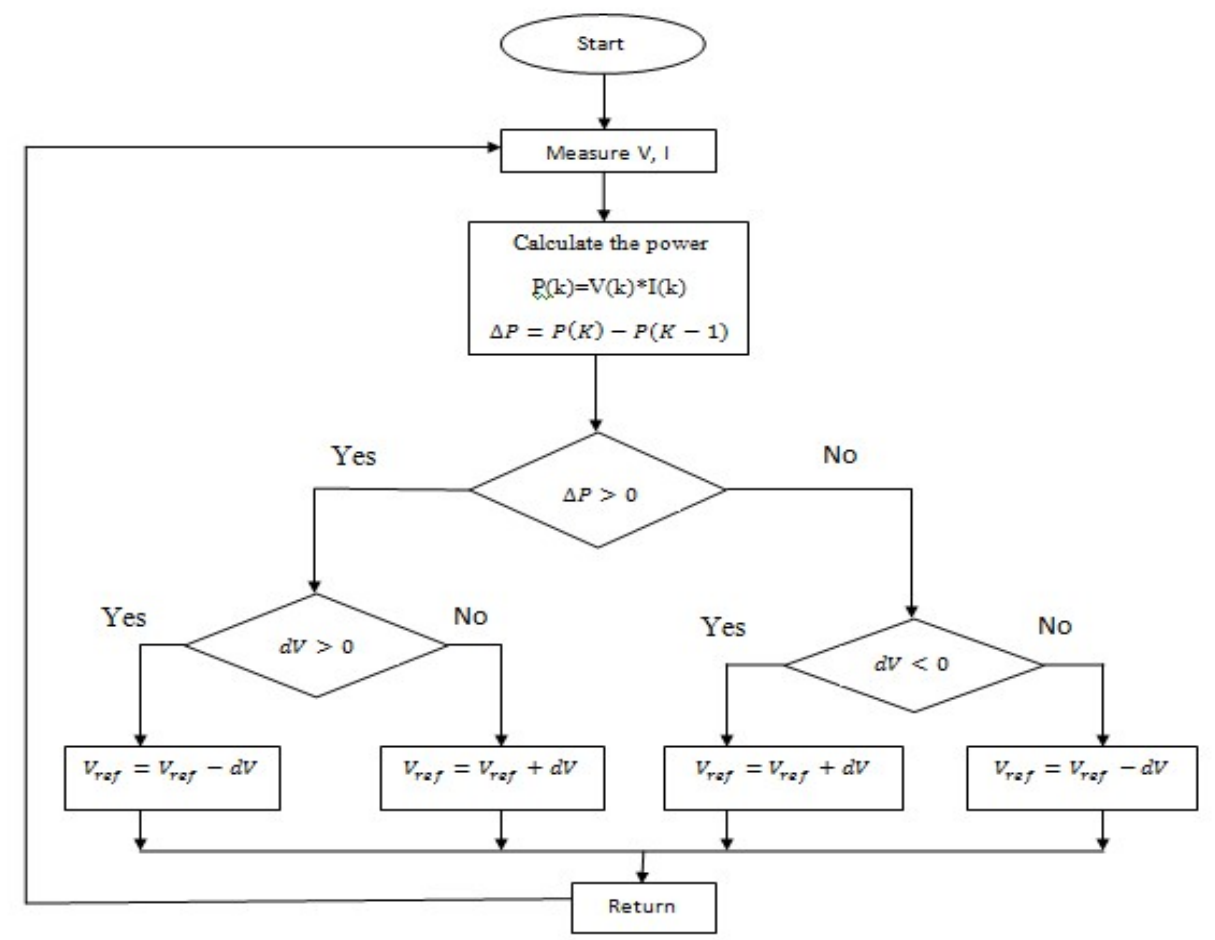

Fig. 2: Flow Chart of $P$ \& O Method 


\section{Incremental Conductance based PI MPPT}

Incremental Conductance (IC) algorithm is used to overcome the drawbacks of $\mathrm{P} \& \mathrm{O}$ method. It is depending on the derivative performance of the solar PV module power is ' 0 ' at MPP shown in equation (5), positive values at the left of MPP as in equation (6) and negative values at the right of MPP shown in equation (7). The algorithm is operated based on the connection between instant conductance $(\mathrm{I} / \mathrm{V})$ and Incremental Conductance $(\Delta \mathrm{I} / \Delta \mathrm{V})[7]$.

$\frac{\Delta I}{\Delta V}+\frac{I}{V}=0 \quad$ at MPP

$\frac{\Delta I}{\Delta V}+\frac{I}{V}>0 \quad$ Left of MPP

$\frac{\Delta I}{\Delta V}+\frac{I}{V}<0 \quad$ Right of MPP

This algorithm gives inaccurate results for lower irradiations. A new parameter $\varepsilon$ is implemented as in equation (8) to solve the above problem.

$\frac{\Delta I}{\Delta V}+\frac{I}{V} \leq \varepsilon$

Fig. 3 shows the flowchart of INC algorithm. Where $\mathrm{D}$ is step-size of perturbation and $\partial$ is duty cycle. The amplitude of the oscillations is regulated by the value of $\varepsilon$ around the MPP. It reduces with the rise in $\varepsilon$ and the operating point moves away from the real MPP for a comparatively higher value of $\varepsilon$. In order to improve the efficiency of the MPPT system, the value of $\varepsilon$ should be accurately determined [8].

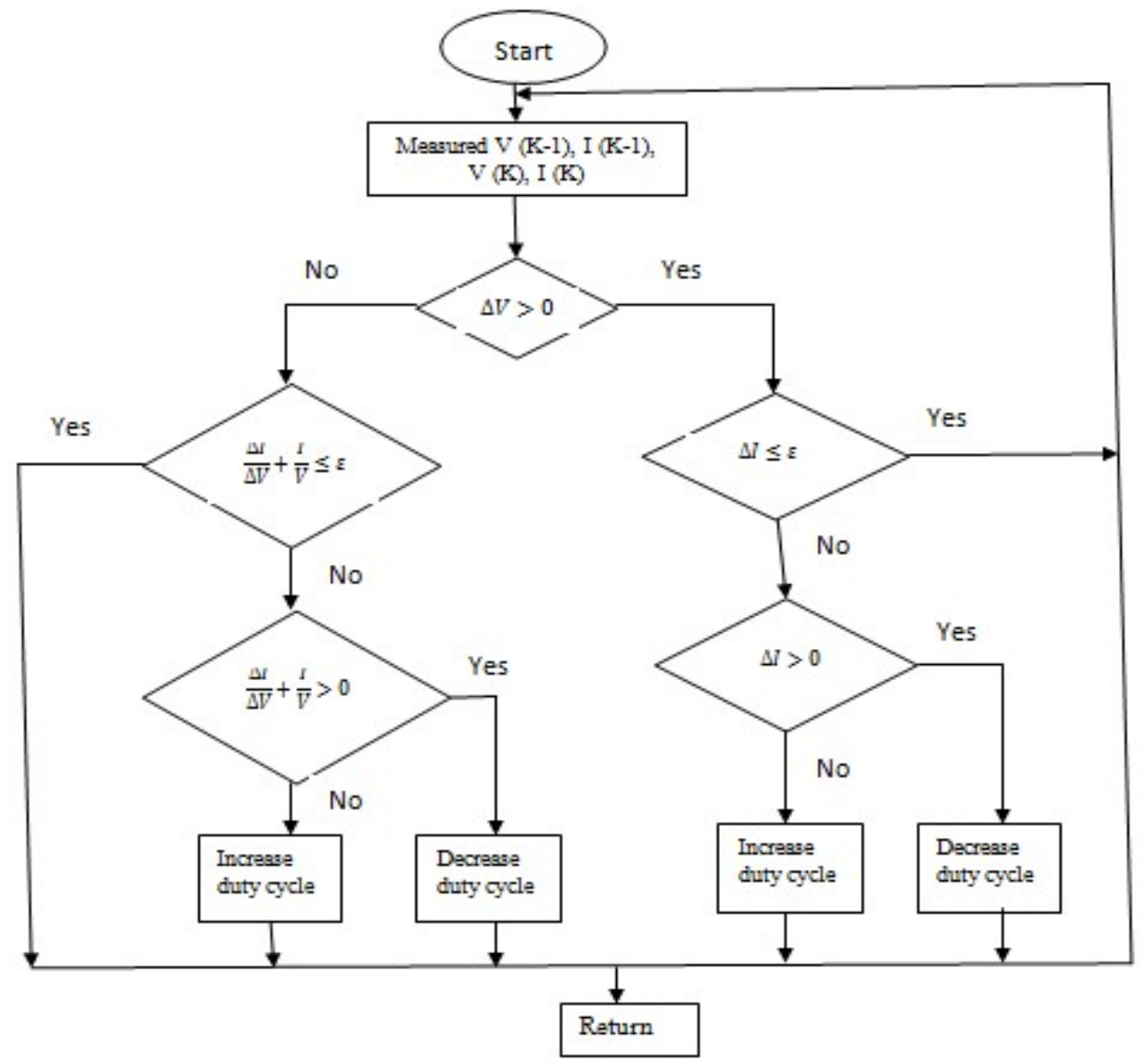

Fig. 3: Flow Chart of INC Method 


\section{PI Controller}

Fig.4 shows the PI controller block diagram. PI controller is a feedback control loop that calculates error signal by taking a system output difference. Proportional integral control is employed to manage the end voltage \& also the power of step-down converter. Ziegler - Nichols methodology is employed to select the Kp and Ki. Kp is effectual to decrease the boost up time and it is inexact solution to reduce the error. The Ki is helpful to reduce the steady state error. Proportional integral control is connected to buck device to maintain the constant voltage [4].

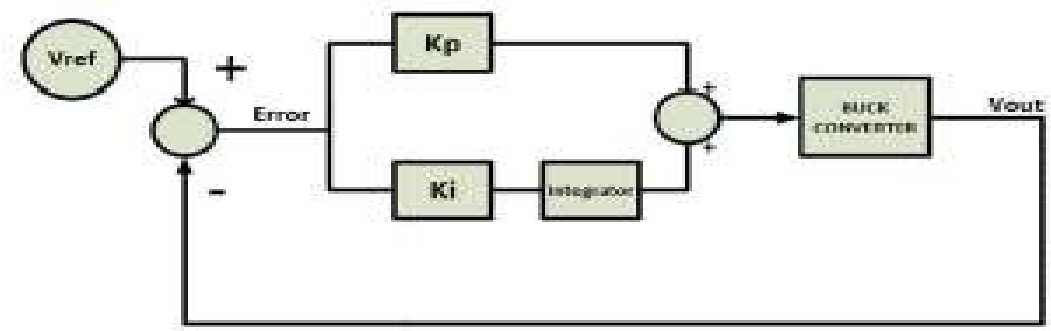

\section{DC - DC Converters}

Fig. 4: Block Diagram of PI Controller

\section{Step-up Converter}

Step-up converter is also called as step-up chopper. MOSFET is used as a switch in this chopper. MOSFET is in ON state during $0<\mathrm{t}<\mathrm{DT} \&$ diode is reversed, the voltage across inductor $\mathrm{V}_{\mathrm{L}}=\mathrm{V}_{\mathrm{in}}$. Switch is in OFF state during DT $<$ $\mathrm{t}<\mathrm{T}$ and diode is forwarded [9], the inductor voltage is $\mathrm{V}_{\mathrm{L}}=\mathrm{V}_{\mathrm{in}}-$ Vout. During steady state situation transform of inductor current must be 0 at the time of switching [11].

Equation (9) represents the duty cycle of step-up converter. Duty cycle is calculated based on input and output voltage. Inductance and capacitance values are calculated by using equation (10) and (11) respectively.

$$
\begin{array}{lr}
\text { Duty cycle } & \mathrm{D}=1-\frac{\mathrm{V}_{\mathrm{s}}}{\mathrm{V}_{\mathrm{o}}} \\
\text { Inductance } & \mathrm{L}=\frac{\mathrm{V}_{\mathrm{s}} \cdot\left(\mathrm{V}_{\mathrm{O}}-\mathrm{V}_{\mathrm{S}}\right)}{\Delta \mathrm{I}_{\mathrm{Lf}} \mathrm{V}_{\mathrm{o}}} \\
\text { Capacitance } & \mathrm{C}=\frac{\mathrm{I}_{\mathrm{o}} \cdot \mathrm{D}}{\mathrm{f}_{\mathrm{S}} \Delta \mathrm{V}_{\mathrm{o}}}
\end{array}
$$

Where $\mathrm{Vs}=$ input voltage, $\mathrm{Vo}=$ Output voltage, $\mathrm{fs}=$ Switching frequency

\section{Step-down Converter}

Step-down converter is also called as step-down chopper. The switch is in ON state during $0<\mathrm{t}<\mathrm{DT}$, diode becomes reverse. The voltage across inductor is $V_{L}=V_{\text {in }}-V_{\text {out }}$. Whereas the switch is OFF state during DT $<\mathrm{t}<\mathrm{T}$, diode conducts and the inductor voltage is $V_{L}=-V_{\text {out }}$. During steady state process, transform of current is zero [9]. Equation (12) represents the duty cycle of step-down converter. Duty cycle is calculated based on input and output voltages. Inductance and capacitance values are calculated by using equations (13) and (14) respectively.

Duty cycle $\quad D=\frac{V_{o}}{V_{S}}$

Inductance $\quad L=\frac{V_{o} \cdot\left(V_{o}-V_{S}\right)}{f_{S} \cdot \Delta I_{L} \cdot V_{S}}$

Capacitance $\quad C=\frac{\Delta \cdot I_{L}}{8 . f_{s} \Delta V_{r p l}}$

Where $\mathrm{V}_{\mathrm{s}}=$ Input voltage, $\mathrm{V}_{0}=$ Output voltage, $\mathrm{f}_{\mathrm{s}}=$ Switching frequency

\section{Simulation Results and Discussion}

Different MPPT techniques are used to simulate the MPP monitoring for solar PV system. The mathematical modeling of a one diode model is developed and designed using MATLAB simulation. The performance is evaluated by multiple curves based on temperature and irradiation conditions. 
Solar PV System without Controller

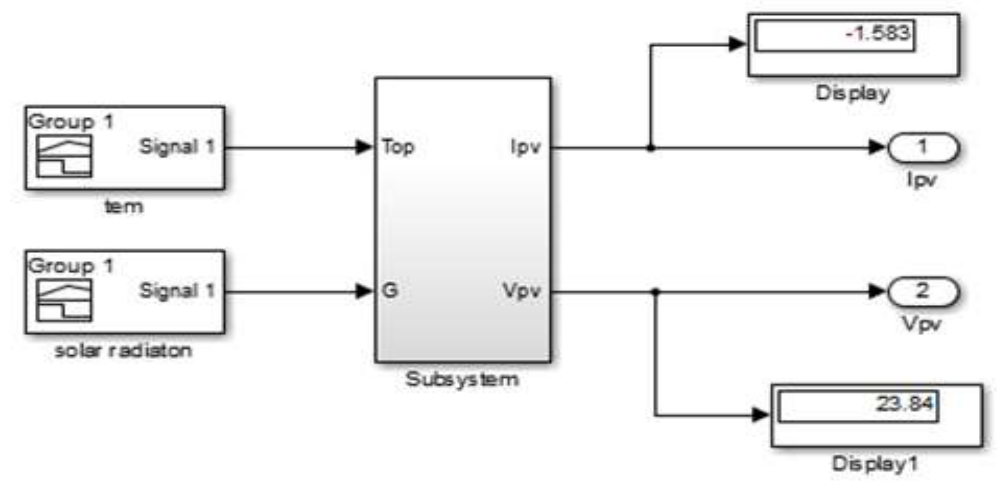

Fig. 5: Simulation Diagram of PV System

Table 1: Specifications of Solar PV System

\begin{tabular}{|l|l|}
\hline Open circuit voltage (Voc) & $24 \mathrm{~V}$ \\
\hline Short circuit current (Isc) & $5.1 \mathrm{~A}$ \\
\hline Voltage at MPP (Vmpp) & $22 \mathrm{~V}$ \\
\hline Current at MPP(Impp) & $4.8 \mathrm{~A}$ \\
\hline Power ofMPP (Pmpp) & $105.6 \mathrm{w}$ \\
\hline Temperature co-efficient of open circuit voltage (\%deg C) & -0.36099 \\
\hline Temperature coefficient of Isc (\%deg C) & 0.102 \\
\hline
\end{tabular}

Fig. 5 shows the simulation diagram of solar photovoltaic system. PV system inputs are temperature and irradiance and outputs are current and voltage. Table.1 shows the specifications of solar PV system.

Case-I: Constant temperature and Variable irradiances

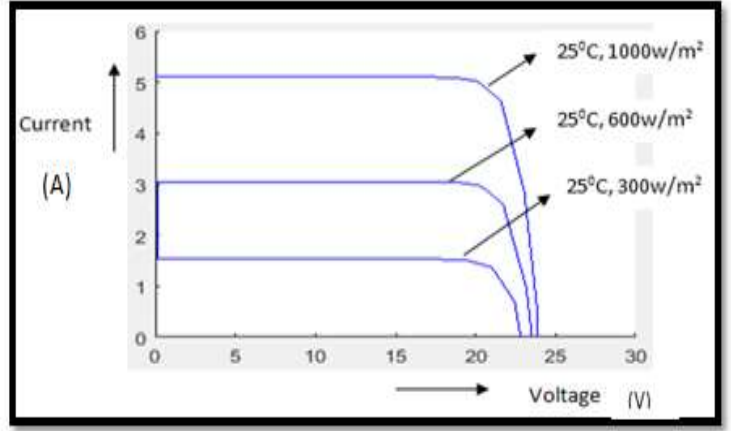

Fig. 6: Effect of Irradiance Variation on I-V Curves

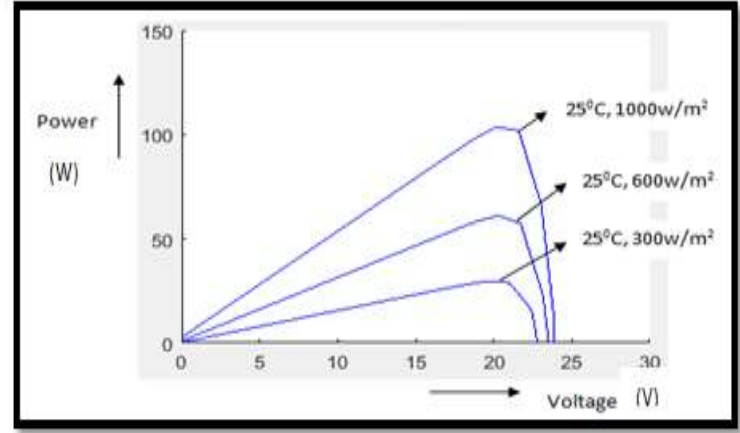

Fig. 7: Effect of Irradiance Variation on P-V Curves 
Case-II: Different temperatures and Constant irradiance

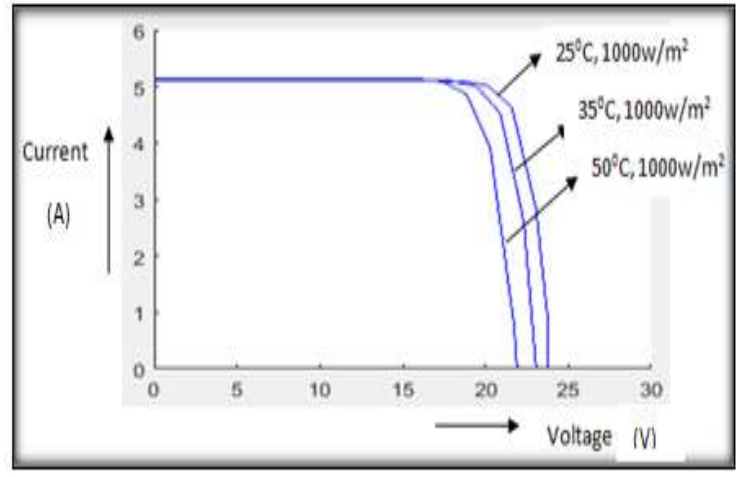

Fig. 8: Effect of Temperature Variation on I-V Curves

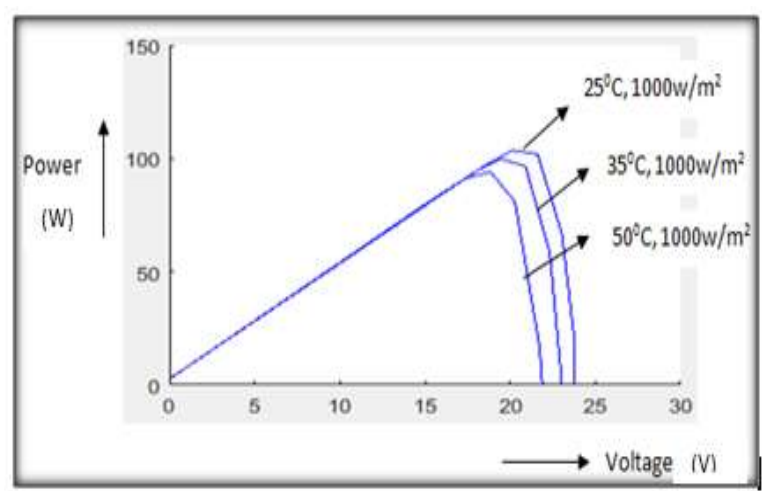

Fig. 9: Effect of Temperature Variation on P-V Curves

Fig.6, Fig.7 and Fig.8, Fig.9 shows the I-V and P-V curves. By observing the above graphs I, V and power values are changed.

\section{Boost Converter}

Fig.10 shows the simulation diagram of boost converter. It is also called as step-up chopper or DC - DC converter. Output waveform of step-up chopper is shown in Fig.11. Initially voltage is suddenly increases \& oscillates and settles at particular point.

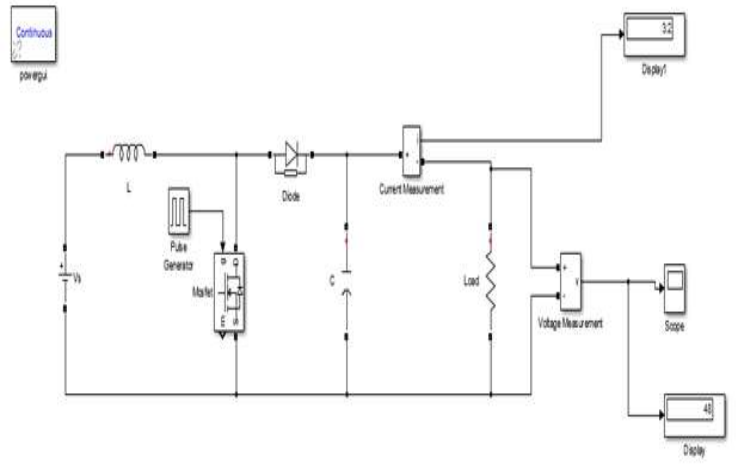

Fig. 10: Simulation Diagram of Step-up Converter

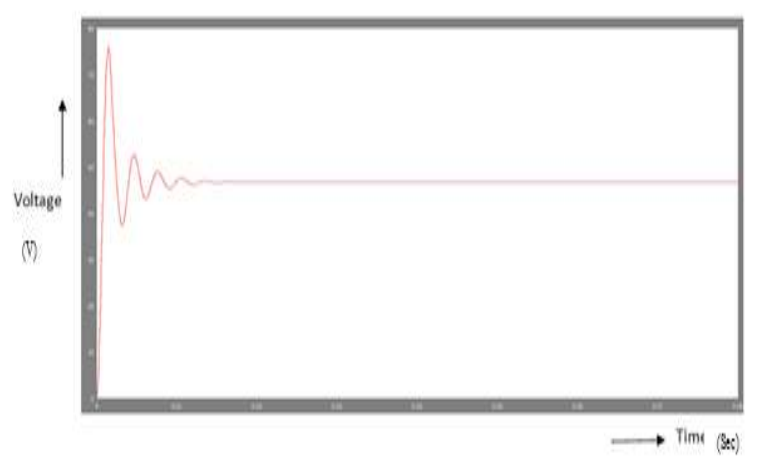

Fig. 11: Output Voltage Waveform of Step-up Converter

\section{Solar PV System with Boost Converter, P \& O MPPT and INC based PI MPPT}

Fig. 12 shows the solar PV system with step-up converter and P \& O and INC based PI MPPT. Solar photovoltaic system inputs are temperature and irradiance and outputs are current and voltage. The electrical PV system and stepup device are connected with the assist of controlled voltage source. The step-up chopper is connected to the controlled voltage source. Voltage and currents are measured by measurement blocks. The outputs of measurement blocks are connected to the MPPT blocks. 


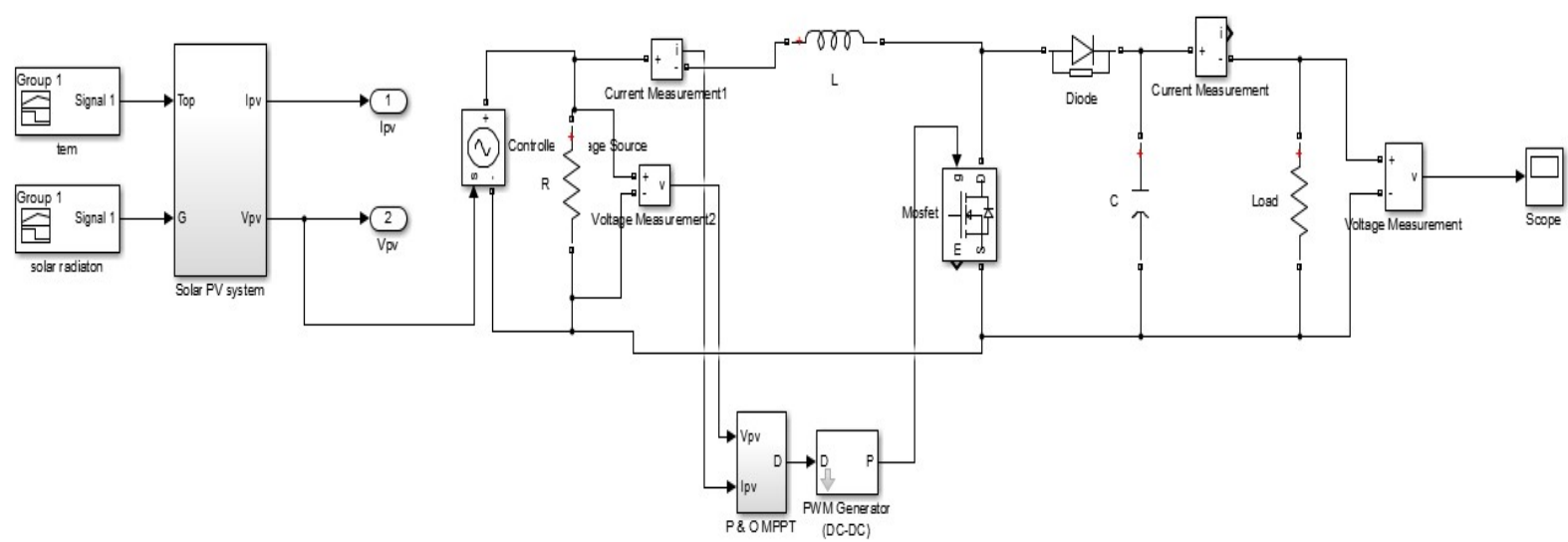

Fig. 12: Simulation Diagram of Solar System with Step-up Chopper and P \& $O$ and INC PI based MPPT

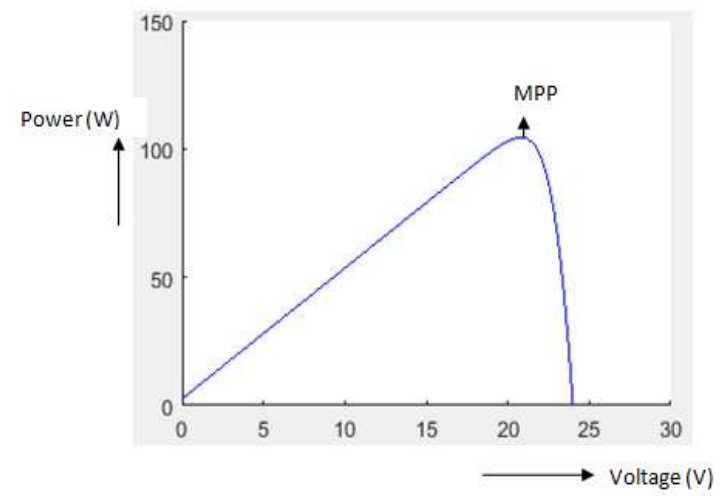

Fig. 13: P-V Curve of P\&O and INC PI MPPT(Case-1)

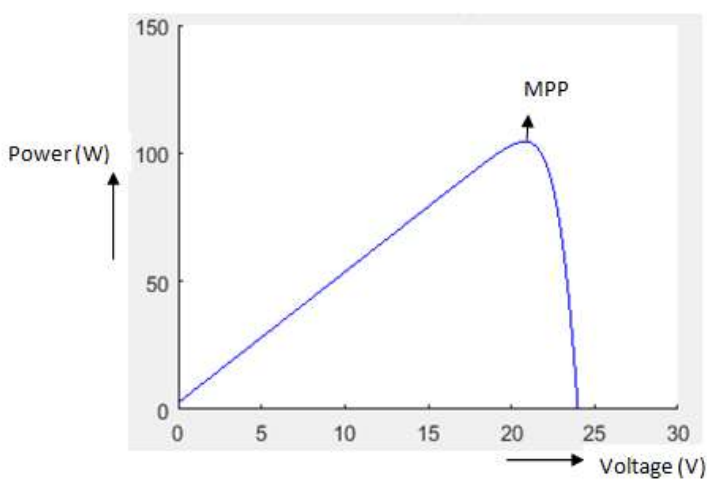

Fig. 14: P-V Curve of P\&O and INC PI MPPT

(Case-2)

Fig.13 and Fig.14 shows the power-voltage curves for P \&O and INC based PI MPPT. From the graphs it is observed that, the power is increased simultaneously. It has improve steady state value but low dynamic performance and more oscillations at the time of MPP tracking. Depending upon load, power-voltage curve also changes.

\section{Buck Converter with PI Controller and Battery}

Fig .15demonstrates the buck converter simulation diagram with PI and battery. Step-down chopper output voltage is stored in battery and maintains constant voltage by using PI controller. Here, we are using two batteries, each battery consists of $12 \mathrm{~V}$. Battery is used to maintain constant voltage. Table 2 shows the battery specifications.

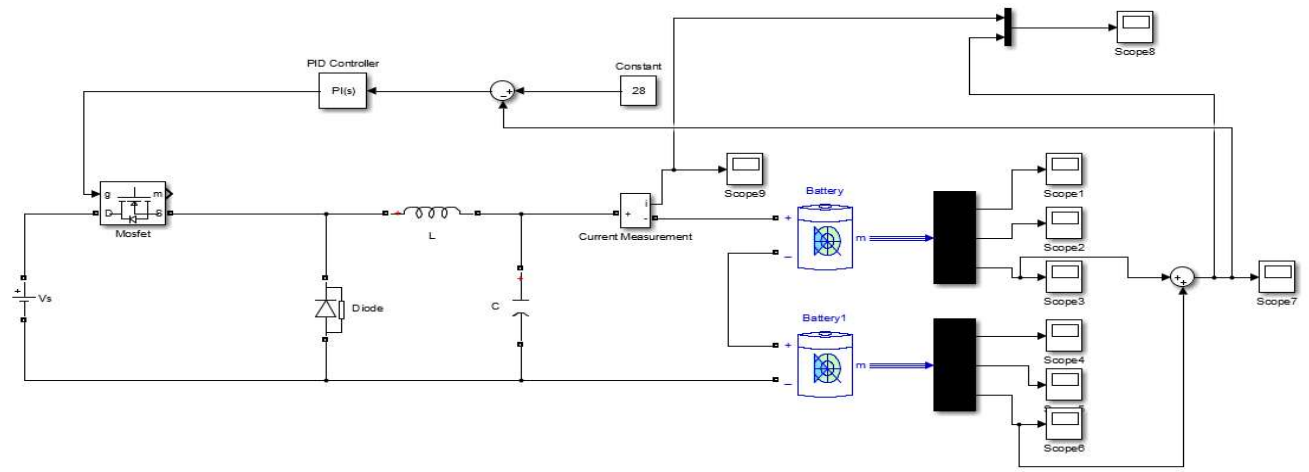

Fig. 15: Simulation Diagram of Step-down Chopper with PI Controller and Battery 
Table 2: Specifications of battery [12]

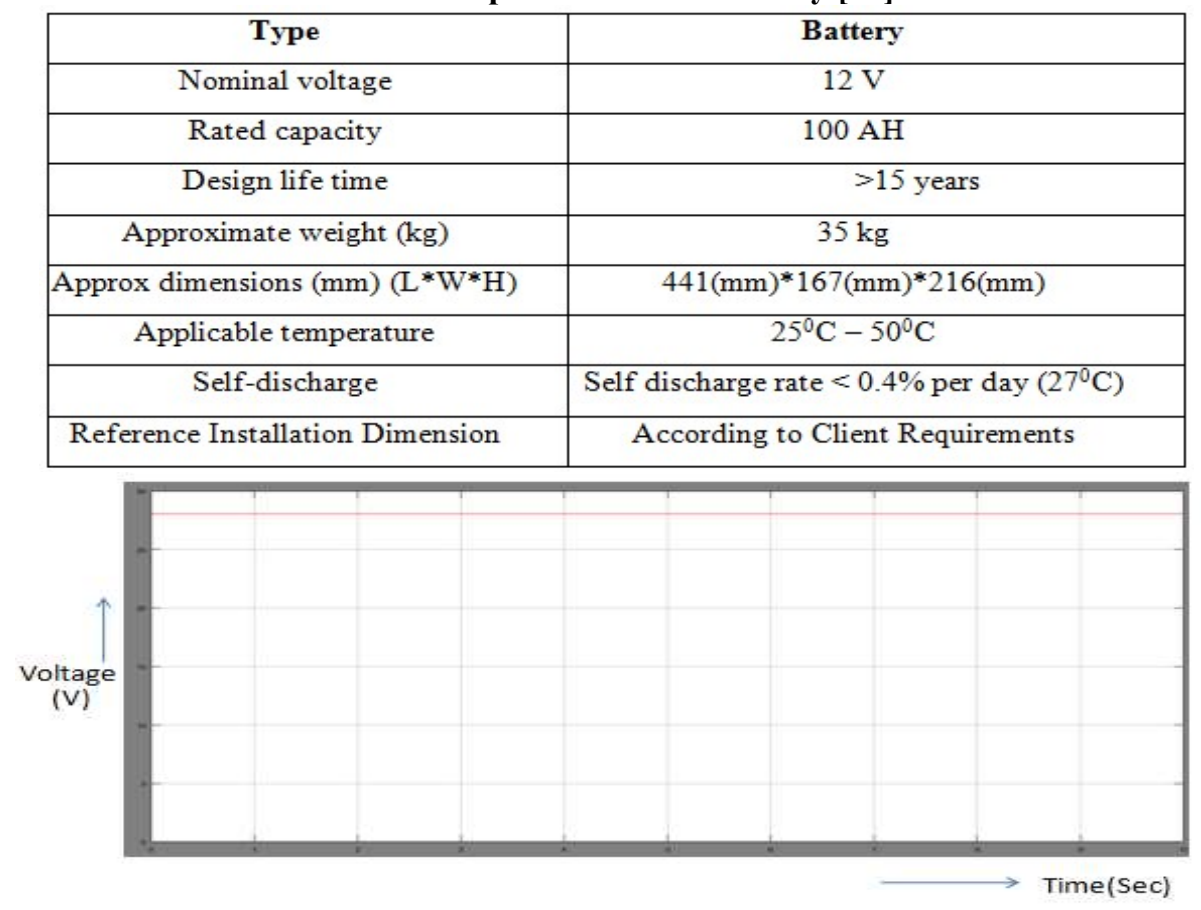

Fig. 16: Output Waveform of Step-down Chopper with PI and Battery

Fig.16 shows the output waveform of step-down device with proportional integral controller and battery. The output response of step-down device with battery has some ripples at the time of starting. Whenever PI controller was applied to the system ripples are reduced and the output voltage will be settled at particular point.

Solar PV System with Boost, Buck and MPPT Techniques

Fig. 17 shows the simulation diagram of solar system with step-up, buck and MPPT techniques. Solar photovoltaic system inputs are temperature and irradiance and outputs are current and voltage. PV system and step-up device is attached with the controlled voltage source. Controlled voltage source is attached to the step-up and step-down converter. Voltage and currents are measured with measurement blocks. The outputs of measurement blocks are connected to the MPPT technique like P \& O and INC based PI. Output waveform of these MPPT techniques is maintained constant as shown in Fig.18.

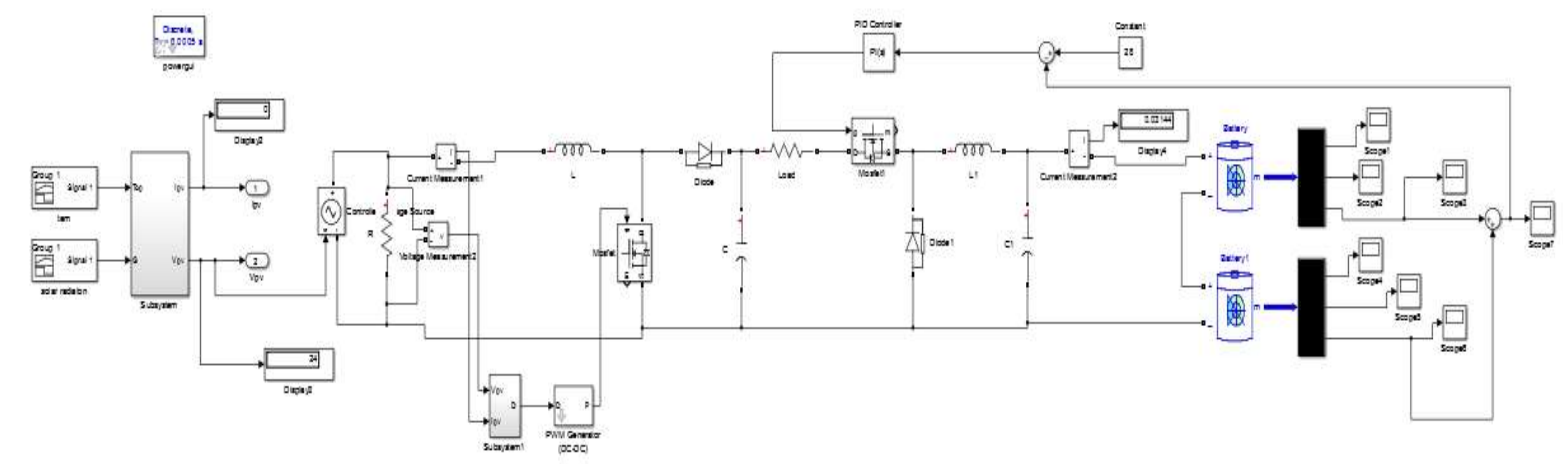

Fig. 17: Simulation Diagram of Solar System with Step-up, Buck and MPPT 


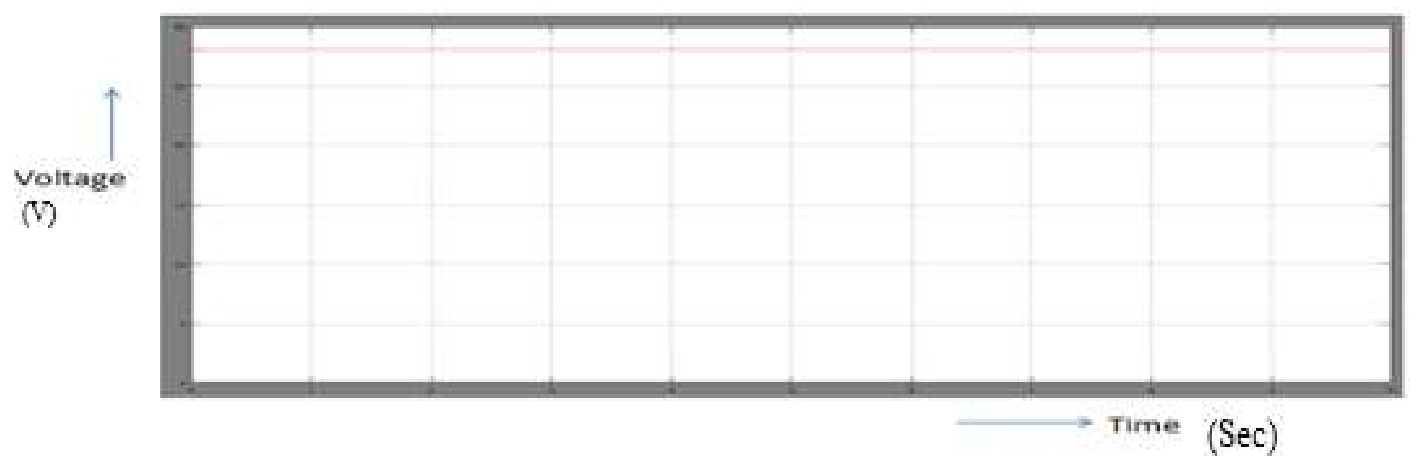

Fig. 18: Output Waveform of Solar PV System with Step-up, Buck and MPPT

Table 3: MPPT Power at Constant Temperature and Different Irradiance

\begin{tabular}{|c|c|c|c|c|c|}
\hline $\begin{array}{c}\text { S.N } \\
\text { o }\end{array}$ & $\begin{array}{c}\text { Constant } \\
\text { temperature }\left({ }^{\circ} \mathrm{C}\right)\end{array}$ & $\begin{array}{c}\text { Different } \\
\text { irradiance }\left(\mathrm{w} / \mathrm{m}^{2}\right)\end{array}$ & $\begin{array}{c}\text { Power at without } \\
\text { MPP }(\mathrm{W})\end{array}$ & $\begin{array}{c}\text { Power at P \& O } \\
\text { based MPPT (W) }\end{array}$ & $\begin{array}{c}\text { Power at INC } \\
\text { based PI MPPT } \\
(\mathrm{W})\end{array}$ \\
\hline 1 & 25 & 300 & 29 & 29.8 & 30 \\
\hline 2 & 25 & 600 & 60 & 61.3 & 61.49 \\
\hline 3 & 25 & 1000 & 103.5 & 104.34 & 104.54 \\
\hline
\end{tabular}

Table 3 shows the MPPT power at constant temperature and different irradiance. Temperature is $25^{\circ} \mathrm{C}$ and different irradiances are $1000,600,300 \mathrm{w} / \mathrm{m}^{2}$. Without controller MPP power at $25^{\circ} \mathrm{C}, 1000 \mathrm{w} / \mathrm{m}^{2}$ is $103.5 \mathrm{~W}$. When MPPT techniques like P \& O, INC based PI are applied to the system, it increases the power to 104.34W, 104.5W respectively. While reduceing irradiance value power values are also reduceing. By comparing these two MPPT techniques the incremental conductance based PI controller has maximum power and gives accurate results and also it improves the efficiency. Fig. 19 shows the graphical representation of results at constant temperature and differnent irradiance.

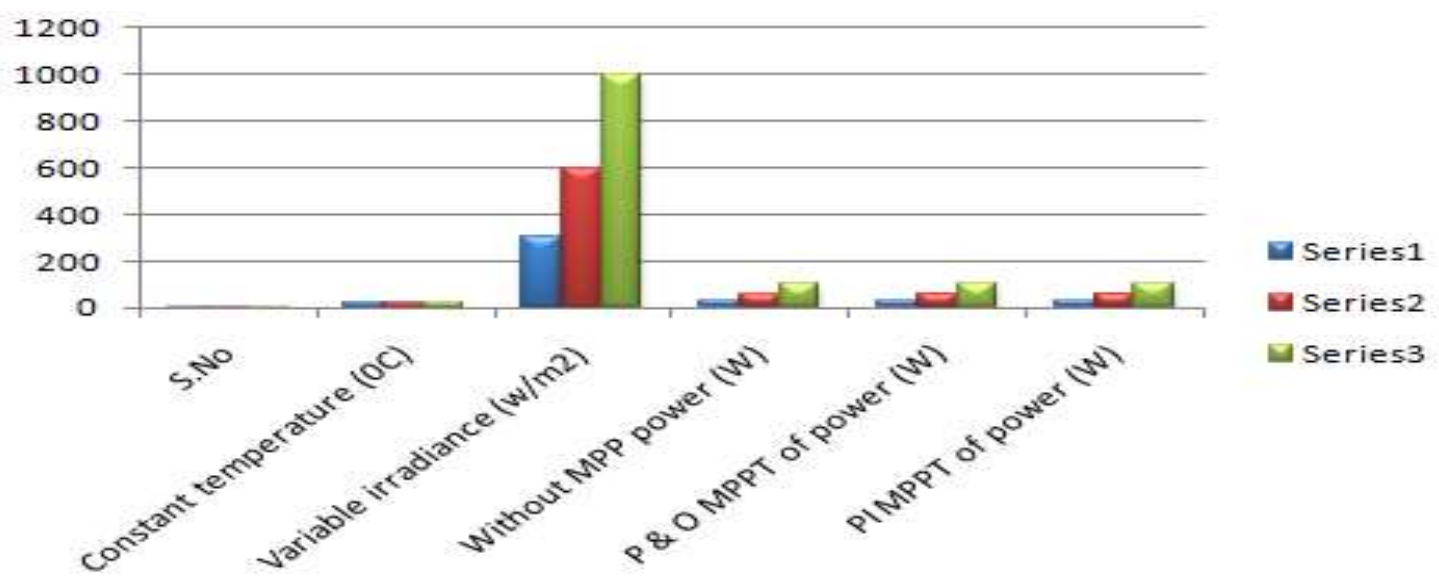

Fig. 19: Graphical Representation of Results at Constant Temperature and Variable Irradiance.

Table 4: MPPT Power at Constant Irradiance and Variable Temperature

\begin{tabular}{|c|c|c|c|c|c|}
\hline $\begin{array}{c}\text { S. } \\
\text { No }\end{array}$ & $\begin{array}{c}\text { Variable } \\
\text { irradiance }\left(\mathrm{w} / \mathrm{m}^{2}\right)\end{array}$ & $\begin{array}{c}\text { Constant } \\
\text { temperature }\left({ }^{0} \mathrm{C}\right)\end{array}$ & $\begin{array}{c}\text { Power at without } \\
\text { MPP }(\mathrm{W})\end{array}$ & $\begin{array}{c}\text { Power at P \& O } \\
\text { based MPPT }(\mathrm{W})\end{array}$ & $\begin{array}{c}\text { Power at INC } \\
\text { based PI MPPT }\end{array}$ \\
\hline 1 & 1000 & 25 & 103.5 & 104.3 & 104.5 \\
\hline 2 & 1000 & 35 & 97.76 & 99.7 & 100 \\
\hline 3 & 1000 & 50 & 90.67 & 93.8 & 94 \\
\hline
\end{tabular}


Table 4 shows the MPPT power at constant irradiance and variable temperature. Variable temperatures are $25^{\circ} \mathrm{C}, 35^{\circ} \mathrm{C}$, $50^{\circ} \mathrm{C}$ and constant irradiance is $1000 \mathrm{w} / \mathrm{m}^{2}$. Without controller MPP power at $25^{\circ} \mathrm{C}, 1000 \mathrm{w} / \mathrm{m}^{2}$ is $103.5 \mathrm{~W}$. When MPPT techniques like P \& O and INC based PI are applied to the system, it increases the power to $104.3 \mathrm{~W}$ and 104.5Wrespectively. While increasing temperature value power values are reduceing. By comparing these two MPPT techniques the incremental conductance based PI has maximum power and gives more accurate and it also improves the efficiency. Fig.20 shows the graphical representation of results at constant temperature and different irradiance.

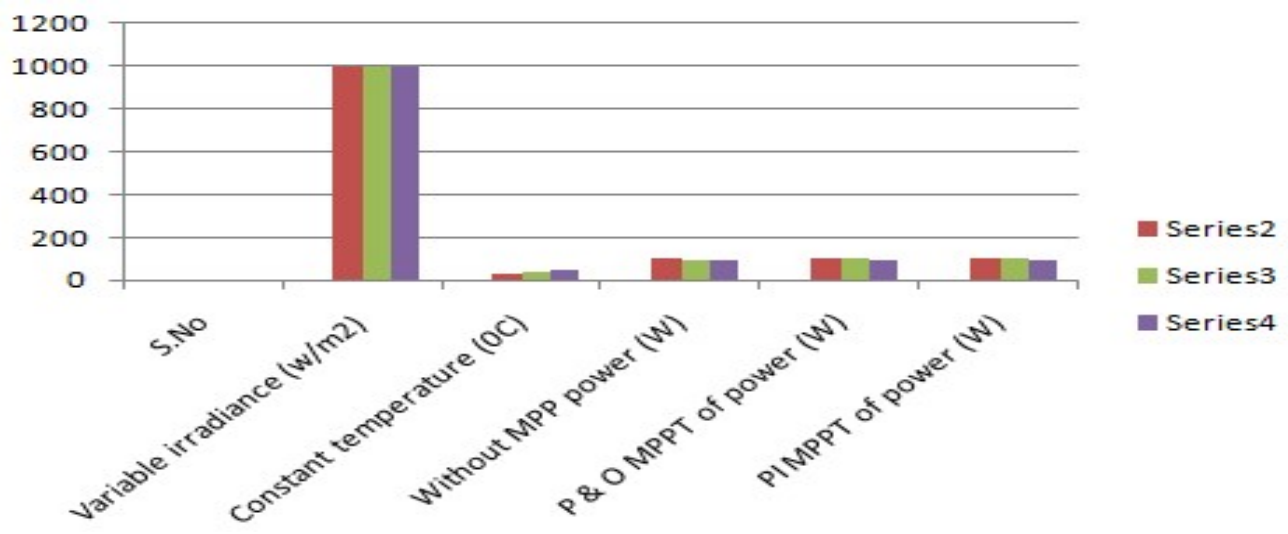

Fig. 20: Graphical Representation of Results at Constant Temperature and Variable Irradiance.

Table 5: Comparison Table of Different MPPT Techniques

\begin{tabular}{|c|c|c|}
\hline Type & P \& O & INC PI \\
\hline Tracking speed & Medium & High \\
\hline Tracking accuracy & Medium & Accurate \\
\hline Implementation complexity & Easy & Medium \\
\hline Dynamic response & Low & Medium \\
\hline Periodic tuning & Not required & Required \\
\hline Power oscillations & More & Medium \\
\hline
\end{tabular}

Table 5 shows the comparison of P\&O and INC based PI. By observing these two techniques proposed Incremental conductance based PI technique has higher tracking speed, more tracking accuracy, higher dynamic response and lower periodic oscillations.

\section{Conclusions}

The proposed technique is tested at two different climatic conditions such as constant irradiation and different temperatures, constant temperature and different irradiations. The solar PV system output is contrasted with two MPPT controllers such as P\&O and IC based PI controller. In this two controllers incremental conductance based PI controller obtaining best performance as comparing to the P\&O. INC based PI controller solar PV system operates effectively in terms of MPP and also maintains the constant voltage \& appropriate current for the battery. This will reduce the system loses and improves the battery life cycle.

\section{References}

1. Yihao Wan, Minqxuan Mao, Lin Zhou, Qianjin Zhang and Chen Zheng "A novel nature-inspired maximum power point tracking (MPPT) controller based on SSA-GWO algorithm for partial shaded photovoltaic systems" Electronics 2019, pp.1-17.

2. G. Ali Akbar, S. Seyed Mohammad, and S. Asma, "A high performance maximum power point tracker for PV systems,” Elect. Power Energy Syst. vol. 53, pp. 237-243 and 2013.

3. Jana J, Bhattacharya KD, Saha H. Design \& implementation of MPPT algorithm for battery charging with photovoltaic panel using FPGA. IEEE 2014:1-5.

4. Unal Yilmaz, Ali Kiracy, Selim Borekci. "PV system fuzzy logic MPPT method and PI control as a charge controller", Renewable and Sustainable Energy Reviews, vol 81, January 2018, pp. 994-1001.

5. Latif T, Hussain Syed R. "Design of a charge controller based on SEPIC and Buck topology using modified Incremental Conductance MPPT", In: Proceedings of the 8th international conference on electrical and computer engineering. Dhaka, Bangladesh; 20-22 December, 2014. 
6. H. A. Sher et al., "A new sensorless hybrid MPPT algorithm based on fractional short-circuit current measurement and P\&O MPPT," IEEE Trans. Sustain. Energy, vol.6, no. 4, Oct.2015, pp.1426-1434.

7. Eid A. Gouda, Mohamed. F. Kotb, and Dina A. Elalfy "Modelling and Performance Analysis for a PV System Based MPPT Using Advanced Techniques",EJECE, European Journal of Electrical and Computer Engineering, vol.3, January 2019, pp.1-7.

8. Mohamed, R.G., Ebrahim, M.A., Bendary, F.M. and Osman, S.A.A. "Transient Stability Enhancement for 20 MW PV Power Plant via Incremental Conductance Controller", International Journal of System Dynamics Applications (IJSDA), 6(4), pp.102-123.

9. Takun P, Somyot Kaitwanidvilai S, Jettanasen C. "Maximum power point tracking using fuzzy logic control for photovoltaic systems" 2011 preceedings of the international multi conference of engineer and computer scientist 2011. IMECS 2011; vol. 2, pp. 1-3.

10. Ramagiri Yerriswamy and M.S.Sujatha "Reactive power support to PV Grid system using voltage source converters to enhance PV penetration level" IOSR-JEEE 2016. pp. 43-50.

11. Kolsi S, Samet H, Ben Amar M. "Design analysis of DC-DC converters connected to a photovoltaic generator and controlled by MPPT for optimal energy transfer throughout a clear day", $J$ Power Energy Eng 2014, vol 2, pp. 27-34.

12. http://www.upsbatteries.co.in/other\%20pdf/ups-batteries-data-sheet-12v-100Ah.pdf 